\title{
ChemComm
}

Check for updates

Cite this: Chem. Commun., 2022, 58,2034

Received 21st September 2021 Accepted 15th November 2021

DOI: $10.1039 / \mathrm{d} 1 \mathrm{cc} 05310 \mathrm{~h}$

rsc.li/chemcomm

\section{Remote ortho-C-H functionalization via medium-sized cyclopalladation}

\author{
Mario Martínez Mingo, ${ }^{a}$ Nuria Rodríguez, (iD *ab Ramón Gómez Arrayás (iD *ab and \\ Juan C. Carretero iD *ab
}

Compared to the tremendous progress made in directed ortho- $\mathrm{C}-\mathrm{H}$ functionalization via five- or six-membered cyclopalladation, protocols with the ability to selectively activate more remote $\mathrm{C}-\mathrm{H}$ bonds through the intermediacy of larger, less favorable, seven- or eight-membered metalacycles are particularly challenging and remain rare. However, such a strategy would provide new retrosynthetic opportunities for generating structural diversity and complexity. Intense recent research based on the use of either mono-anionic bidentate or monodentate directing groups is characterizing this approach as an increasingly viable tool for selective $\mathrm{C}-\mathrm{C}$ and $\mathrm{C}-\mathrm{X}$ bond-forming reactions. This short review provides an overview of these strategies with an emphasis on mechanistic details, synthetic applicability, limitations, and key challenges.

\section{Introduction}

The direct catalytic transformation of $\mathrm{C}-\mathrm{H}$ bonds into new functionalities offers a powerful and versatile means of generating structural diversity and complexity. The great potential, but also the challenges, associated to this strategy are due to the ubiquity of $\mathrm{C}-\mathrm{H}$ bonds in organic substances. ${ }^{1-10}$ Despite the extensive progress made, achieving high site selectivity control is still a prominent goal in the field. ${ }^{11-16}$

A successful approach towards this goal is the use of directing groups (DGs) to assist the $\mathrm{C}-\mathrm{H}$ metalation step. A DG is a Lewis basic entity that acts as a ligand for the metal and brings the active catalytic species into close proximity to the desired C$\mathrm{H}$ bond. This chelation control has a dual role in influencing local reactivity: (i) controlling the energy barrier for $\mathrm{C}-\mathrm{H}$ bond activation and (ii) ensuring the desired selectivity by overriding inherent substrate preferences governed by electronic and/or steric bias. Furthermore, DGs with the ability to be easily removed or transformed allowing product diversification are of great value and actively sought after in this field.

In recent decades, directed $\mathrm{C}-\mathrm{H}$ functionalization through metallacycle formation has been successfully employed in drug discovery and material science as well as pharmaceutical and chemical industries, among others. ${ }^{17-19}$ Nonetheless, the potential of this approach is mostly restricted to reactions that

\footnotetext{
${ }^{a}$ Department of Organic Chemistry, Universidad Autónoma de Madrid (UAM), Facultad de Ciencias, Cantoblanco, 28049, Madrid, Spain.

E-mail: n.rodriguez@uam.es, ramon.gomez@uam.es, juancarlos.carretero@uam.es

${ }^{b}$ Institute for Advanced Research in Chemical Sciences (IAdChem), UAM, Madrid, Spain
}

involve activation of proximal $\mathrm{C}-\mathrm{H}$ bonds (generally beta or gamma to the directing group). In most of these cases, the kinetically preferred formation of five-membered metallacycles dictates selectivity, which is particularly true in the case of palladium catalysis. ${ }^{20}$ Five-membered metalation with $\mathrm{Pd}^{\mathrm{II}}$ leads to the formation of square-planar complexes, whereas six or higher-membered palladacycles display less stable nonplanar coordination. ${ }^{21}$

By contrast, remote functionalization of $\mathrm{C}-\mathrm{H}$ bonds located distal to the DG remains undeveloped. A primary reason for this scarcity is that it requires the formation of metalacycles larger than 5- or 6-membered rings, which are kinetically and thermodynamically disfavored. In this context, the various DG-assisted methodologies that have appeared mainly involve the functionalization of $\mathrm{C}\left(\mathrm{sp}^{2}\right)-\mathrm{H}$ bonds through six-membered palladacycles. Similarly, the meta- or para-selective functionalization of arene derivatives through a template-assisted palladation approach involving the formation of macropalladacycles with reduced ring strain (up to larger than 12 membered-rings) has also received significant attention. ${ }^{22-27}$ However, there is only a handful of protocols in the literature capable of achieving directed remote ortho-C-H functionalization via medium sized (7-9-membered) palladacycle intermediates, which highlights the challenging nature of this task. The majority of these examples involve seven-membered rings, with only two contributions proceeding via the intermediacy of eight-membered palladacycles (Scheme 1).

The aim of this review is to bring together these remote ortho-directed $\mathrm{C}\left(\mathrm{sp}^{2}\right)-\mathrm{H}$ bond transformations, through seven or eight-membered palladacycle intermediates, primarily emphasizing mechanistic aspects regarding site selectivity 


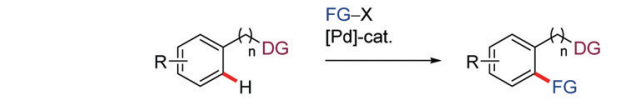

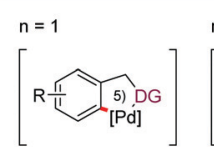

r-Functionalization

$\checkmark$ kinetically favored

$\checkmark$ widely explored

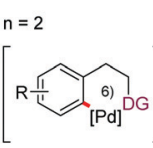

$\delta$-Functionalization

less explored

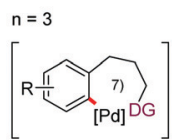

s-Functionalization $\zeta$-Functionalization

$\checkmark$ not favored $\checkmark$ not favored

$\checkmark$ scarcely explored $\checkmark$ virtually not $\checkmark$ less explored

Scheme 1 Five membered $\mathrm{C}\left(\mathrm{sp}^{2}\right)-\mathrm{H}$ versus six, seven and eight membered $\mathrm{C}\left(\mathrm{sp}^{2}\right)-\mathrm{H}$ metalation.

control. The aim of this overview is to stimulate impactful research in the field leading to practical solutions to the existing limitations and challenges. New strategies for selective functionalization of remote $\mathrm{C}-\mathrm{H}$ bonds would provide new retrosynthetic opportunities for the construction of $\mathrm{C}-\mathrm{C}$ and $\mathrm{C}-\mathrm{X}$ bonds.

\section{Formation of $\mathrm{C}-\mathrm{C}$ bonds}

Strategies involving $\mathrm{C}-\mathrm{C}$ bond formation at inert $\mathrm{C}-\mathrm{H}$ bonds have allowed the ready access to molecules that would otherwise be difficult to prepare, involving biologically relevant compounds, modern synthetic materials, and commodity chemicals.

Among the variety of strategies described in the literature, the oxidative alkenylation of arenes (also known as FujiwaraMoritani reaction or direct dehydrogenative Heck-coupling) is among the most prominent. This cross-coupling provides one of the most straightforward ways for the construction of styrene derivatives, which are very important building blocks in the chemical industry. ${ }^{28-33}$ Most of these catalytic $\mathrm{C}\left(\mathrm{sp}^{2}\right)-\mathrm{H}$ transformations involve chelation-control through five- or sixmembered palladacycles. The first example that was proposed to proceed through a seven-membered palladacycle was reported by Shi and Zhao in 2014. In this work, a highly efficient protocol for the Pd-catalyzed oxalylamide (OA)directed mono-selective alkenylation of phenylpropylamine derivatives at $\varepsilon$ position was devised (Scheme 2). ${ }^{34} \mathrm{Pd}(\mathrm{OAc})_{2}$ (10 mol\%) and $\mathrm{Ag}_{2} \mathrm{CO}_{3}$ in super-stoichiometric amount was

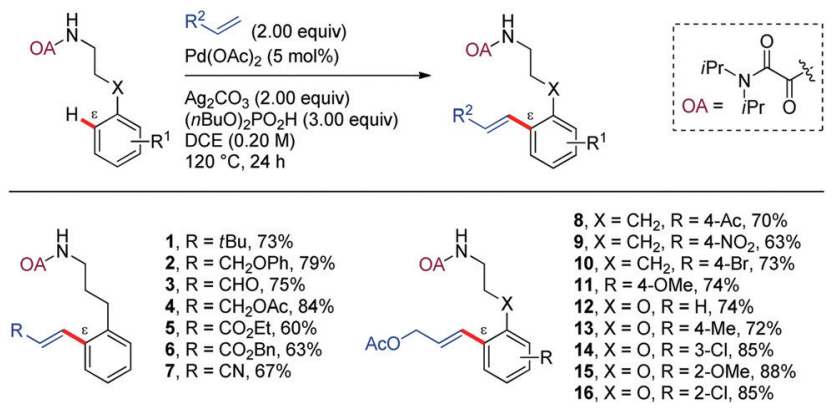

Scheme 2 OA-Directed Pd-catalyzed alkenylation of arylpropyl amines with olefins. found to be the best catalyst and oxidant combination, along with $(n-\mathrm{BuO})_{2} \mathrm{PO}_{2} \mathrm{H}$ as additive in DCE at $120{ }^{\circ} \mathrm{C}$ for $24 \mathrm{~h}$. This method was successfully applied to a wide range of olefins, such as terminal alkyl olefins, allyl alcohol derivatives, acrylaldehyde, allyl acetate, acrylates, and acrylonitrile (1-7). The scope of the reaction includes phenylpropylamine derivatives bearing different substitution patterns in the aromatic ring (8-16). In all cases studied, the methylene $\gamma-\mathrm{C}-\mathrm{H}$ bonds, whose activation would involve five-membered cyclopalladation, remained unaltered. Furthermore, sequential double alkenylation at the two ortho positions with two different olefins provided a practical one-pot method for the synthesis of complex alkenylated arenes in good yields.

Mechanistic experiments in the presence of TEMPO, showing no detrimental effect in reactivity, argued against a radical pathway. The authors postulated a $\mathrm{Pd}^{\mathrm{II}} / \mathrm{Pd}^{0}$ mechanism where the $(n-\mathrm{Bu})_{2} \mathrm{PO}_{2} \mathrm{H}$ may function as a basic ligand that facilitates the $\mathrm{C}-\mathrm{H}$ activation step via a seven-membered ring palladacycle intermediate (Scheme 3). The resulting cyclopalladated complex would subsequently evolve through alkene insertion and $\beta$-hydride elimination to generate the alkenylated phenylpropylamine derivative along with $\mathrm{Pd}^{0}$. Reoxidation of the latter species by the silver salt would close the catalytic cycle. The authors suggested that the typical dialkenylation competing reaction was not favoured in this case due to a weak interaction between the palladium complex and the olefin.

Carretero reported in 2016 a suitable protocol for the Pd-catalyzed 2-pyridylsulfonyl $\left(\mathrm{SO}_{2} \mathrm{Py}\right)$ directed alkenylation of benzyl and phenethylsulfone derivatives with activated olefins (Scheme 4). ${ }^{35}$ In the case of benzyl sulfone derivatives (17-26), the metallacycle resulted from the $\mathrm{C}-\mathrm{H}$ activation cleavage would be a seven-membered intermediate, coordinated by the $\mathrm{N}$-atom from the pyridine moiety. On the other hand, phenethyl sulfone derivatives would lead to the challenging eight membered metalated intermediate (27-36), which has been scarcely investigated. In terms of reactivity, tether length of the DG did

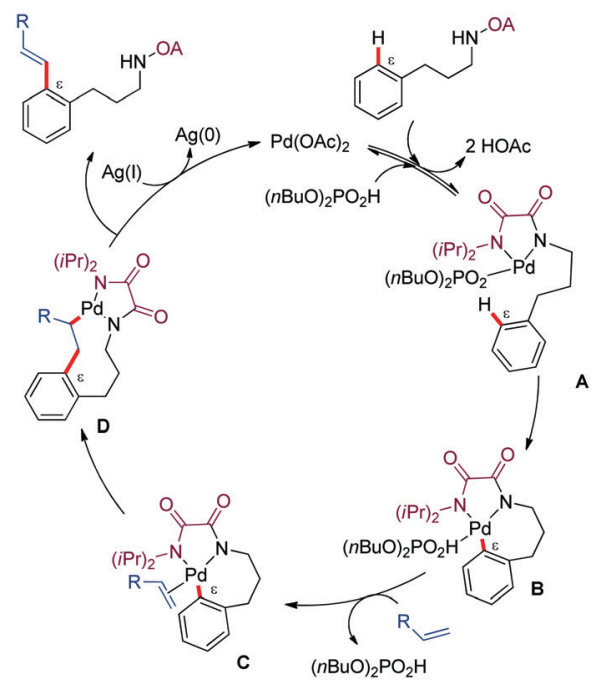

Scheme 3 Mechanistic proposal for the alkenylation of phenylpropyl amine derivatives. 


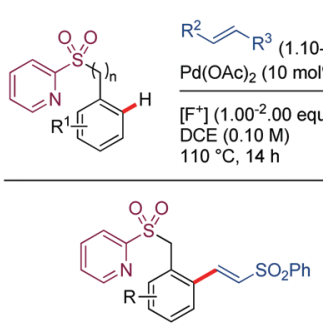

17, $\mathrm{R}=\mathrm{H}, 67 \%$

18, $R=4-\mathrm{OMe}, 64 \%$

19, $\mathrm{R}=4-\mathrm{CF}_{3}, 73 \%$

21, $\mathrm{R}=3-\mathrm{CO}_{2} \mathrm{Me}, 45 \%$

22. $\mathrm{R}=2-\mathrm{Me}, 62 \%$

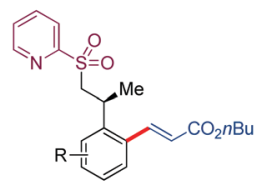

27, $\mathrm{R}=\mathrm{H}, 69 \%(91 \% \mathrm{ee})$

28, $R=4-\mathrm{Me}, 71 \%$

$29, \mathrm{R}=4-\mathrm{OMe}, 69 \%$

$30, \mathrm{R}=4-\mathrm{CF}_{3}, 52 \%$

$31, \mathrm{R}=3-\mathrm{CF}_{3}, 21 \%$

32, $\mathrm{R}=2-\mathrm{Br}, 57 \%$

Scheme 4 Pd-Catalyzed olefination of benzyl and phenethyl sulfone derivatives.

not significantly affect the yield of the product. Tolerance to a broad range of functional groups at both coupling partners, as well as to different substitution patterns on the aromatic ring are attractive features of this alkenylation protocol. In the case of phenethyl sulfone derivatives, substitution at the benzylic position is required to achieve high yields (27-36). Nevertheless, the stereochemical integrity of the stereogenic center at the benzylic position was preserved when using enantiomerically enriched substrates (27). This method was applied to the synthesis of indane derivatives holding three contiguous stereogenic centers upon by an intramolecular Michael-type addition of the $\alpha$-sulfonyl carbanion of phenethyl sulfone derivatives to the newly introduced electrophilic alkene.

Oxidative coupling of $\mathrm{C}-\mathrm{H}$ bonds with alkynyl halides has become a convenient method for introducing an alkyne functionality into aromatic compounds. ${ }^{36-42}$ In most of the reported examples, a five-membered metallacycle is involved in the $\mathrm{C}-\mathrm{H}$ activation process. However, in 2015, Zeng and Zhao reported the ability of the oxalyl amide (OA) as DG in promoting the ortho-alkynylation of phenethylamine and phenylpropylamine derivatives at $\delta$ and $\varepsilon$ positions, respectively (Scheme 5) ${ }^{43}$ While the former functionalization presumably occurred through a six-membered palladacycle, the later implied the formation of a seven-membered ring analogue. Stoichiometric amounts of both AgOAc and KOAc were required to achieve high yields. The authors hypothesized that the acetate ion might act as a proton shuttle during the catalytic cycle, while the role of the silver ion, which was found to be crucial for $\varepsilon^{-}$but not $\delta$-derivatization remained unclear.

Regarding the scope, unsubstituted or para-substituted aromatic rings led to mixtures of mono and di-alkynylated products $(\mathbf{3 7}, \mathbf{4 5})$, while in the case of meta-substitution the reaction

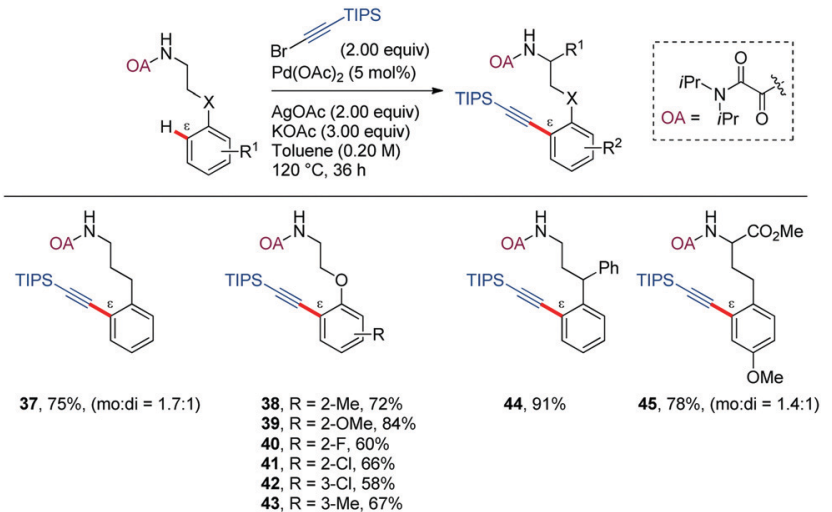

Scheme 5 OA-Directed Pd-catalyzed alkynylation of arylpropyl amines with alkynyl halides.

is preferred at the more sterically accessible $\mathrm{C}-\mathrm{H}$ bond $(\mathbf{4 2 , 4 3 )}$. Substitution at the benzylic position suppressed the formation of the di-alkynylated product, likely due to steric effects (44).

In 2019, we reported a practical method for the construction of benzazepinones through a Pd-catalyzed carbonylative cyclization of $\gamma$-arylpropylamine derivatives, including chiral $\alpha$-amino acids. The use of the 2-pyridylsulfonamide $\left(N-\mathrm{SO}_{2} \mathrm{Py}\right)$ as DG was key for selectively targeting $\mathrm{C}\left(\mathrm{sp}^{2}\right)-\mathrm{H}$ carbonylation at the remote $\varepsilon$-position. This method uses $\mathrm{Mo}(\mathrm{CO})_{6}$ as convenient substitute for $\mathrm{CO}$ gas. The functionalization of further positions failed, as well as the employ of different amide or sulfone based DGs, even the native amine (Scheme 6). ${ }^{44} \mathrm{~A}$ wide variety of substituted $\gamma$-arylpropylamine derivatives were used, noting that substrates bearing electron-rich aryl substituents provided higher reactivity (46-54). The applicability of this method to the derivatization of heteroarenes was showcased by the synthesis of a chiral analogue of rucaparib, a recently approved drug for ovarian cancer (55). Applications to late-stage modification of di- and tripeptides were also demonstrated $(56,57)$.

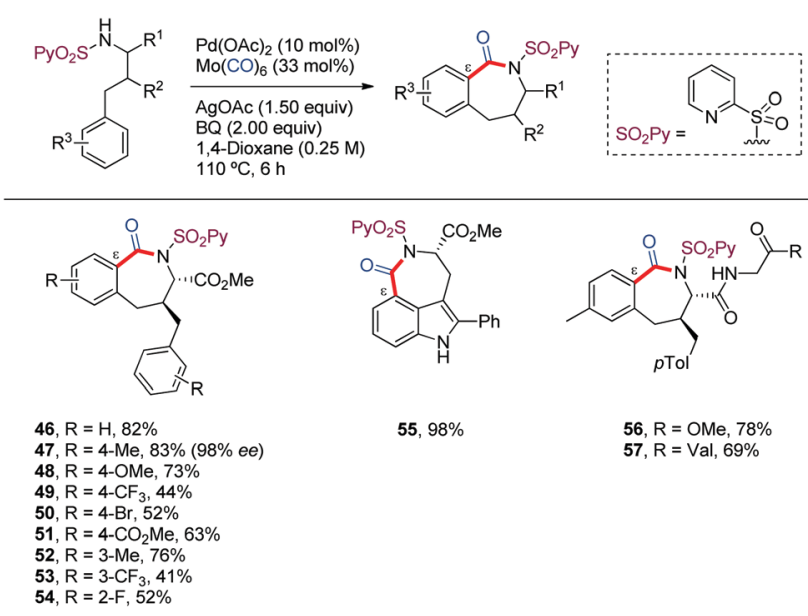

Scheme $6 \mathrm{~N}-\mathrm{SO}_{2}$ Py-directed carbonylative cyclization of $\gamma$-arylpropyl amines. 


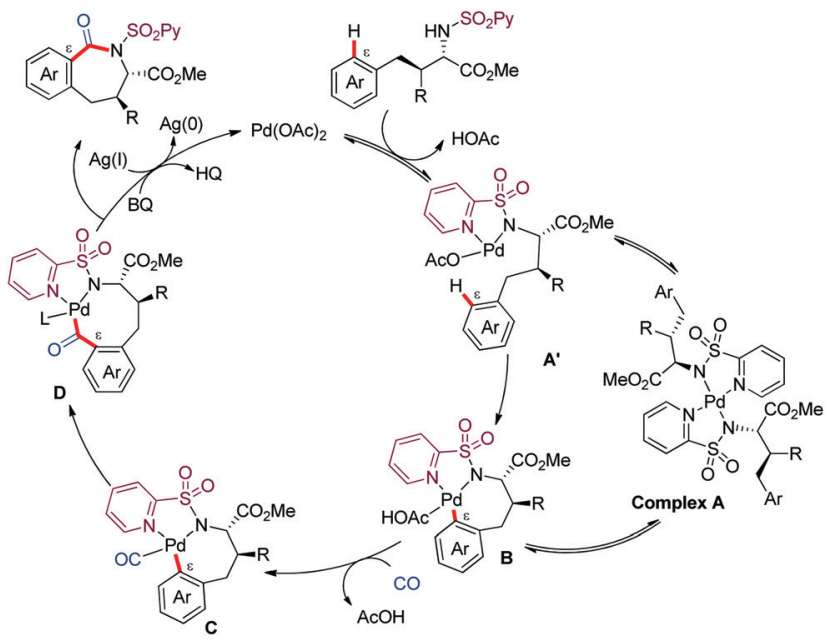

Scheme 7 Mechanistic proposal for the $\varepsilon$-carbonylative cyclization.

We proposed a $\mathrm{Pd}^{\mathrm{II}} / \mathrm{Pd}^{0}$ catalytic cycle initiated by coordination of the substrate to $\operatorname{Pd}(\mathrm{OAc})_{2}$ generating complex $\mathbf{A}^{\prime}$ in equilibrium with complex $\mathbf{A}$ (which serves as reversible off-cycle reservoir) (Scheme 7). Then, the $\mathrm{Pd}^{\mathrm{II}}$-catalyzed $\mathrm{C}-\mathrm{H}$ activation would lead to complex $\mathbf{B}$, which upon coordination to $\mathrm{CO}(\mathbf{C})$ followed by carbonyl insertion across the Pd-C bond could afford complex D. Reductive elimination would next release the benzazepinone product, along with reduced $\mathrm{Pd}^{0}$ species that would then be reoxidized back to the active $\mathrm{Pd}^{\mathrm{II}}$ species via the combined action of BQ and AgOAc.

In the case of $\gamma$-aryl-substituted valine derivatives, which have available both aliphatic $\gamma-\mathrm{C}\left(\mathrm{sp}^{3}\right)-\mathrm{H}$ (via a 5-membered palladacycle) and aromatic $\varepsilon-\mathrm{C}\left(\mathrm{sp}^{2}\right)-\mathrm{H}$ bonds (via a 7-membered palladacycle), chemoselective reaction at $\mathrm{C}\left(\mathrm{sp}^{2}\right)-\mathrm{H}$ bonds consistently predominated over activation of $\mathrm{C}\left(\mathrm{sp}^{3}\right)-\mathrm{H}$ bonds (58-64) (Scheme 8). However, site-selectivity was found to

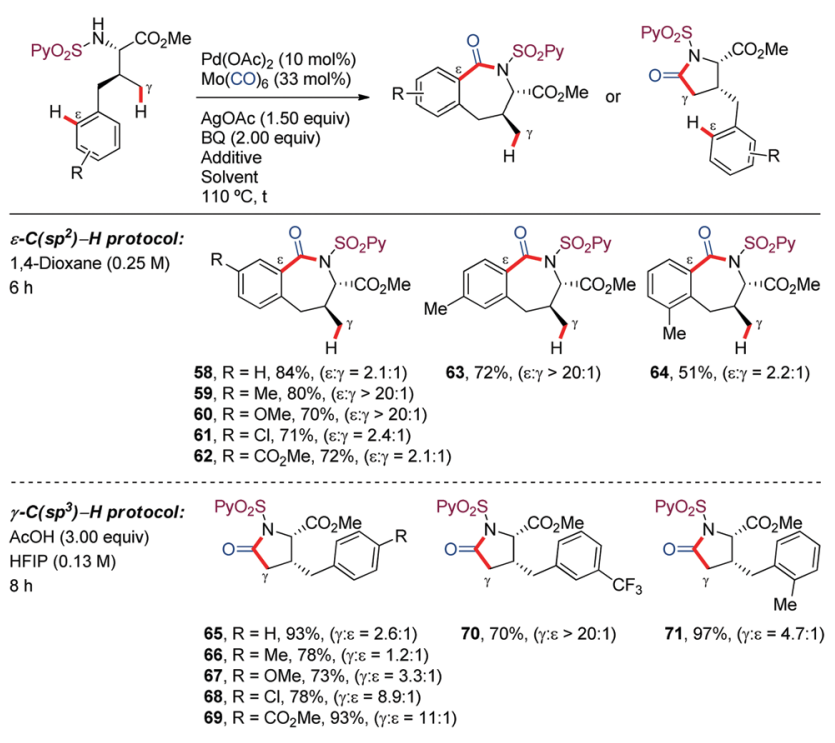

Scheme $8 \quad \mathrm{~N}$ - $\mathrm{SO}_{2} \mathrm{Py}$-directed seven versus five membered functionalization. be sensitive to the electronic properties of the aromatic ring, with aryl activation being more favored for substrates bearing electronrich substituents. Theoretical and experimental mechanistic studies carried out subsequently by our research group revealed that the $\varepsilon-\mathrm{C}\left(\mathrm{sp}^{2}\right)-\mathrm{H}$ bond cleavage in the $\gamma$-arylated valine substrate was significantly faster and more reversible than the $\gamma-\mathrm{C}\left(\mathrm{sp}^{3}\right)-\mathrm{H}$ bond activation. However, the subsequent $\mathrm{CO}$ coordination from the $\mathrm{C}\left(\mathrm{sp}^{3}\right)$-palladacycle led to more stable intermediates from which the reaction was irreversible. ${ }^{45}$ This knowledge provided the basis for the rational identification of reaction conditions that enabled reversing the selectivity from arene $\mathrm{C}\left(\mathrm{sp}^{2}\right)-\mathrm{H}$ activation to $\mathrm{C}\left(\mathrm{sp}^{3}\right)-\mathrm{H}$ cleavage, by promoting thermodynamic over kinetic control, thus leading to $\gamma$-lactam derivatives $(\mathbf{6 5 - 7 1 )})^{45}$ This achievement is remarkable given the high selectivity for arene $\mathrm{C}-\mathrm{H}$ activation over aliphatic $\mathrm{C}-\mathrm{H}$ activation typically displayed by Pd. ${ }^{46-55}$

\section{Formation of $\mathrm{C}-\mathrm{X}$ bonds}

\section{1. $\quad \mathrm{C}-\mathrm{N}$ bond formation reactions}

In a seminal contribution, Daugulis ${ }^{56}$ reported in 2012 the picolinamide (PA)-directed Pd-catalyzed oxidative cyclization of $\mathrm{N}$-protected amines using $\mathrm{PhI}(\mathrm{OAc})_{2}$ as oxidant in toluene at 80-120 ${ }^{\circ} \mathrm{C}$ (Scheme 9a). This methodology allowed access to pyrrolidine, indoline, and isoindoline derivatives in good yields (72-75). The regioselectivity of the $\mathrm{C}-\mathrm{H}$ activation was generally determined by the formation of a [5,6]-palladacycle intermediate. Subsequent oxidation to form high-valent palladium species, followed by $\mathrm{C}-\mathrm{N}$ reductive elimination would lead to the reaction products. Interestingly, the formation of a dihydrophenanthridine from 2,6-diphenylbenzylamine, involving the construction of a six-membered ring, showed that cyclopalladation via a seven-membered ring is also feasible through this method (Scheme 9b). However, only a single example of this type of $\varepsilon$-functionalization was disclosed (76).

Shortly after, Chen demonstrated the generality of this direct $\mathrm{C}-\mathrm{H} / \mathrm{N}-\mathrm{H}$ oxidative cyclization by developing a two-step method for the synthesis of phenanthridines from easily

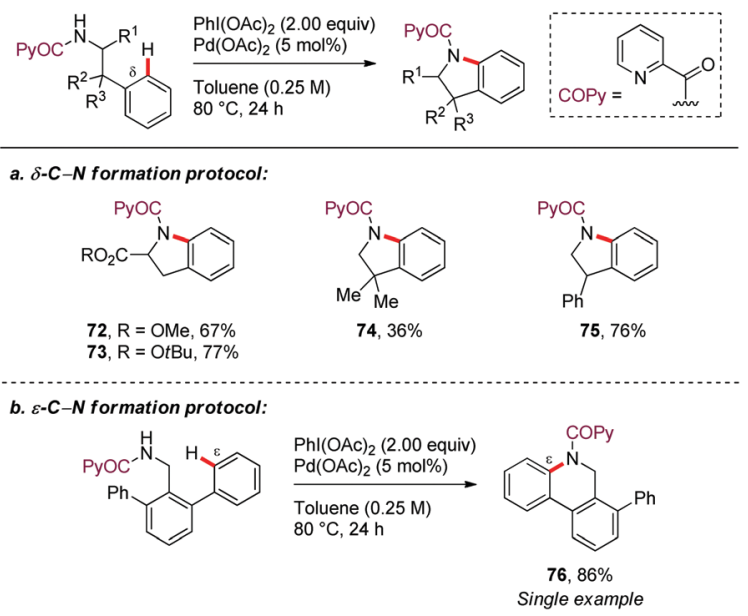

Scheme 9 PA-Directed formation of dihydrophenanthridine derivatives. 


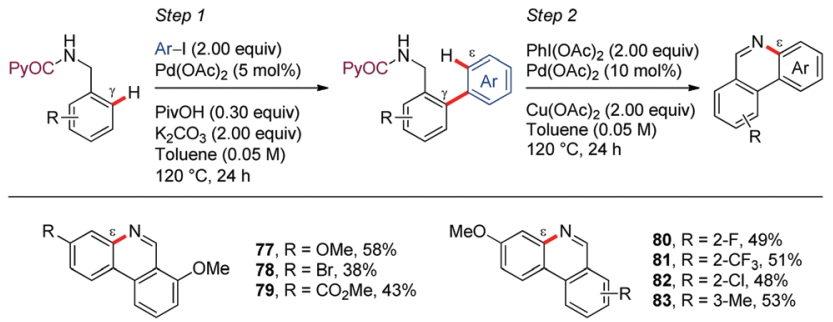

Scheme 10 PA-Directed formation of phenanthridine derivatives.

accessible PA-protected benzylamine derivatives (Scheme 10). ${ }^{57}$ In the first step, an improved protocol for the Pd-catalyzed PAdirected ortho-C-H arylation with iodoarenes was devised that avoids using expensive silver additives. Next, the intramolecular dehydrogenative coupling was achieved under Pd-catalysis using $\mathrm{PhI}(\mathrm{OAc})_{2}$ and $\mathrm{Cu}(\mathrm{OAc})_{2}$ as oxidants, affording the corresponding phenanthridine derivatives (77-83). The ortho-selectivity in the first step is dictated by a five-membered palladacycle intermediate, whereas the intermediacy of a sevenmembered metallacycle is assumed for controlling $\varepsilon$-selectivity in the second step. In general, electron-rich arene motifs provided better yields than electron-deficient substrates.

In 2014, Yao and Zhao ${ }^{58}$ reported a novel protocol for the Pd-catalyzed $\varepsilon$-selective intramolecular $\mathrm{C}\left(\mathrm{sp}^{2}\right)-\mathrm{H}$ amination of $\gamma$-arylpropylamine derivatives using an oxalyl amide as $N$, $N$-bidentate DG (Scheme 11). Tetrahydroquinoline and benzomorpholine derivatives were efficiently assembled in good yields in the presence of $\mathrm{PhI}(\mathrm{OAc})_{2}$ as oxidant under low catalyst loading $(3 \mathrm{~mol} \%)$ and mild conditions $\left(60{ }^{\circ} \mathrm{C}\right)$, thus enabling wide group tolerance (84-98).

$\mathrm{H} / \mathrm{D}$ scrambling studies performed in the absence of $\mathrm{PhI}(\mathrm{OAc})_{2}$ revealed a high H/D exchange at the $\varepsilon$-position (99$\mathrm{D}, 62 \% \mathrm{H} / \mathrm{D}$ scrambling) but not at the $\gamma$-methylene position, suggesting that the $\mathrm{Pd}^{\mathrm{II}}$-catalyzed aryl $\mathrm{C}-\mathrm{H}$ bond cleavage is reversible (Scheme 12).

\section{2. $\mathrm{C}-\mathrm{O}$ bond formation reactions}

$\mathrm{C}-\mathrm{O}$ bond formation, especially acetoxylation, has received substantial attention driven by the importance of the acetoxy group in organic synthesis. An additional complication inherent to any remote $\mathrm{C}-\mathrm{H}$ oxygenation process of amine derivatives is how to prevent the competitive intramolecular $\mathrm{C}-\mathrm{H}$ amination leading to the kinetically and thermodynamically favoured
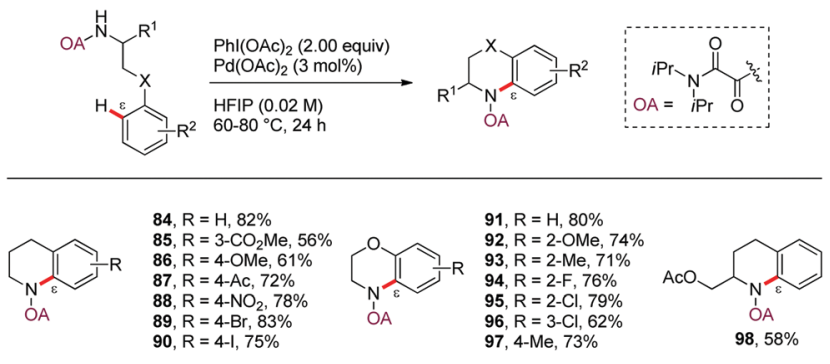

Scheme 11 Oxalyl amide directed Pd-catalyzed intramolecular amination of arylpropyl amines.

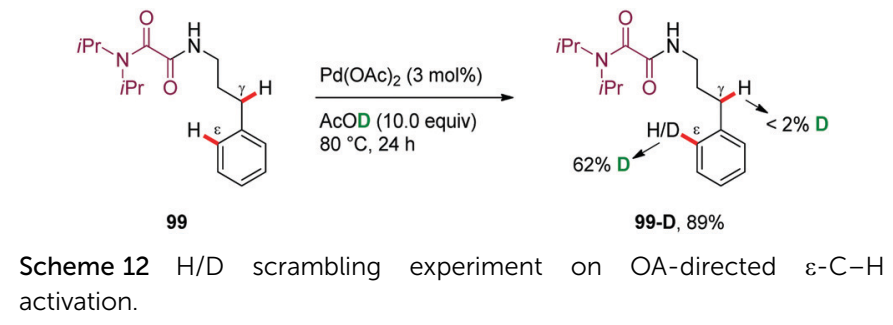

cyclized products. In many cases, the formation of the intermolecular $\mathrm{C}-\mathrm{H}$ oxygenation or intramolecular $\mathrm{C}-\mathrm{H}$ amination product depends on the substrate. ${ }^{59-62}$

The first example of a remote $\mathrm{C}-\mathrm{H}$ oxygenation reaction assumed to presumably proceed through a seven-membered palladacycle was reported by $\mathrm{Yu}$ in 2010 (Scheme 13). ${ }^{63}$ In this work, the ortho-C-H acetoxylation of phenlyethyltriflamides, likely via six-membered ring cyclopalladation, is described using tert-butyl peroxyacetate as the stoichiometric oxidant and either DMF or $\mathrm{CH}_{3} \mathrm{CN}$ as the promoter. However, an isolated example on the $\varepsilon$-acetoxylation of a $\gamma$-phenylpropylamine derivative, having a one atom longer tether, was reported, showcasing the feasibility of extending this method to the intermediacy of seven-membered palladacycles. Nevertheless, the yield of the isolated product remained low (100).

Along similar lines, $\mathrm{Babu}^{64}$ reported in 2016 a chemoselective Pd-catalyzed ortho-acetoxylation of PA-protected (furan-2yl)- or (thien-2-yl)methanamine derivatives with $\mathrm{PhI}(\mathrm{OAc})_{2}$ (101-110) (Scheme 14). Among the bidentate DGs tested, picolinamide (PA) and pyrazine-2-carboxamide (PyrA) were the most effective in the $\varepsilon-\mathrm{C}-\mathrm{H}$ acetoxylation (111), whereas the oxalylamide (OA) showed lower efficiency (112). However, removal of the bidentate DG from the acetoxylated biaryl systems was found to be difficult. Interestingly, when a 2-(thien-2yl)benzylamine derivative having the complementary biaryl system was subjected to identical reaction conditions, the oxidative cyclization product was obtained instead of the $\varepsilon-\mathrm{C}-\mathrm{H}$ acetoxylated product (113) (Scheme 15). This result highlights that this transformation is strongly substrate dependent.

The authors tentatively suggested a $\mathrm{Pd}^{\mathrm{II}} / \mathrm{Pd}^{\mathrm{IV}}$ catalytic pathway (Scheme 16). Bidentate coordination of the DG-linked substrate and subsequent $\mathrm{C}-\mathrm{H}$ bond cleavage would lead to a metalated $[5,7]$-bycyclic intermediate (A). Subsequent oxidation to $\mathrm{Pd}^{\mathrm{IV}}$ species type-B by $\mathrm{PhI}(\mathrm{OAc})_{2}$, followed by reductive elimination would afford the $\varepsilon$-acetoxylated product along with $\mathrm{Pd}^{\mathrm{II}}$.

\section{3. $\quad \mathrm{C}-\mathrm{I}$ bond formation reactions}

Iodination of aryl $\mathrm{C}-\mathrm{H}$ bonds provides a straightforward access to synthetically valuable building blocks. In 2008, $\mathrm{Yu}^{65}$

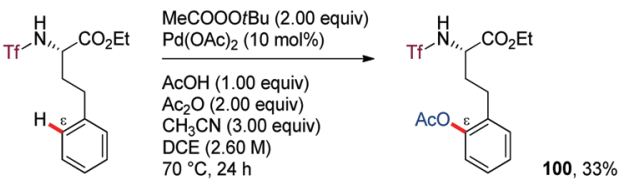

Scheme 13 ortho-Acetoxylation of a triflamide derivative. 

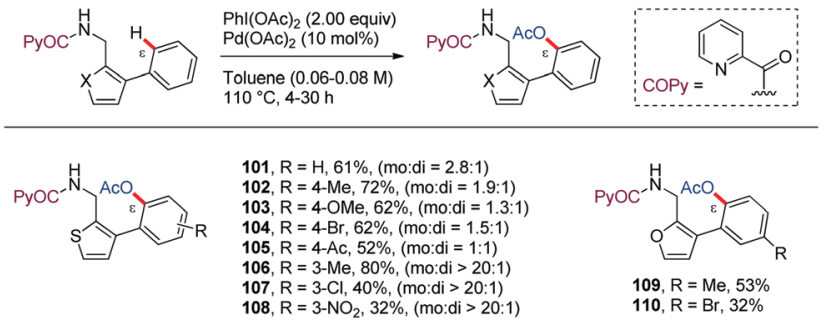

Extension to other directing groups

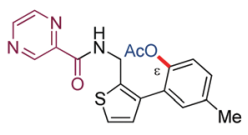

$111,57 \%$

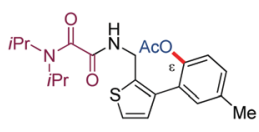

$112,48 \%$

Scheme $14 \mathrm{Pd}$-Catalyzed $\varepsilon$-acetoxylation of heteroaryl-aryl type biaryl systems.
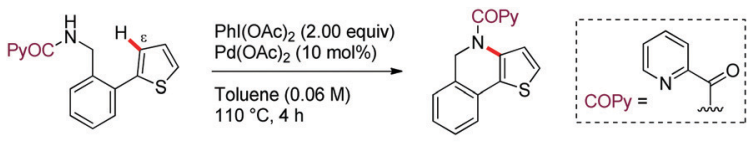

$113,50 \%$

Scheme $15 \varepsilon-C-N$ Bond formation of 2-thiophenyl-benzyl picolinamide derivative.

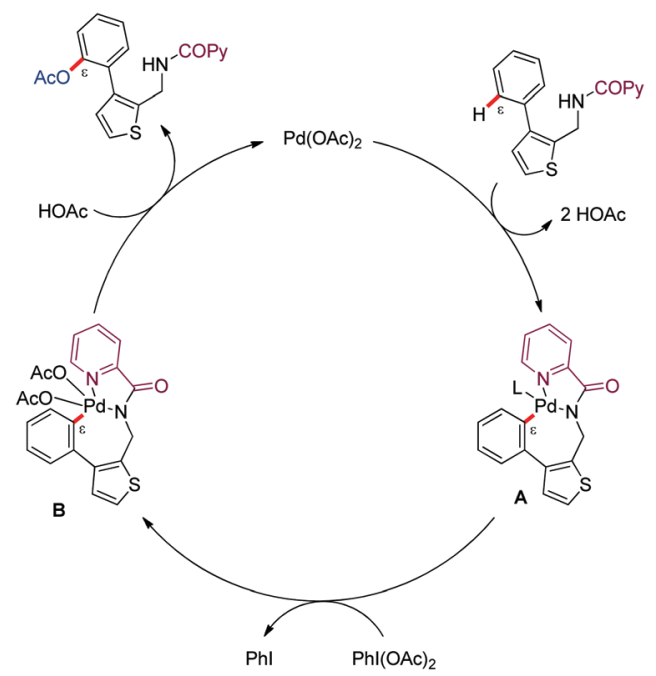

Scheme 16 Mechanistic proposal for the acetoxylation of biaryl systems.

described the iodination of aryl $\mathrm{C}-\mathrm{H}$ bonds located four, five or even six bonds away from the oxazoline DG using $\mathrm{Pd}(\mathrm{OAc})_{2}$ as the catalyst and IOAc as both oxidant and iodine source (114-118) (Scheme 17).

Systematic kinetic isotope studies revealed a mechanistic regime shift as the tether length of the DG to the target $\mathrm{C}-\mathrm{H}$ bond increases. The authors tentatively proposed that the functionalization of nearby $\mathrm{C}-\mathrm{H}$ bonds proceeded via an oxidative addition mechanism or a $\sigma$-bond metathesis mechanism $(\mathrm{KIE}=3.5)$ whereas the more remote $\mathrm{C}-\mathrm{H}$ bond activation

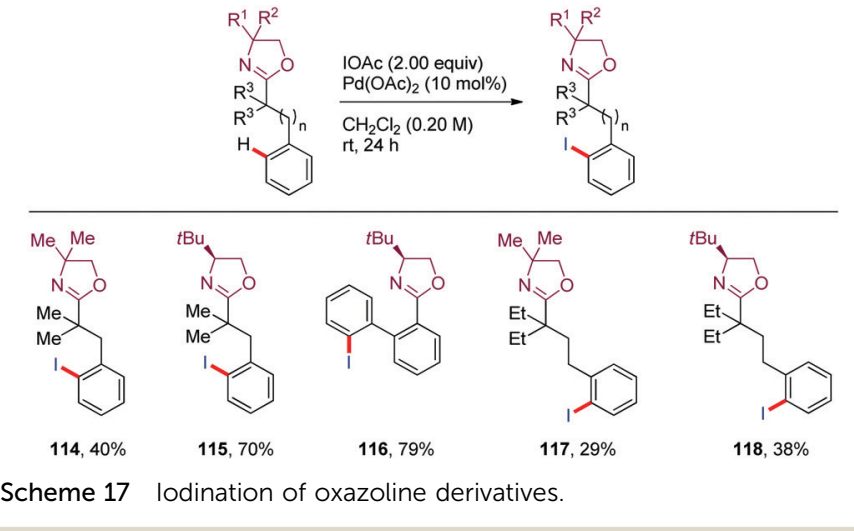

seemed to occur through an electrophilic palladation pathway based on both isotope $(\mathrm{KIE}=1.5)$ and electronic effects observed. In the latter cases, the initial palladation appears to be slower than the $\mathrm{C}-\mathrm{H}$ bond cleavage.

\section{Summary and outlook}

In the past decades, a variety of DGs have been designed for controlling the chelate-assisted direct functionalization of arenes mainly through either five- or six-membered palladacycle intermediates. These new methods have found application in the synthesis of a wide range of functionalized molecules and bioactive compounds. However, the successful use of DGs capable of selectively facilitating the direct activation of more remotely located $\mathrm{C}-\mathrm{H}$ bonds remains an outstanding challenge. Most of the few examples reported in the literature involve the remote ortho- $\mathrm{C}\left(\mathrm{sp}^{2}\right)-\mathrm{H}$ bond functionalization of amine derivatives using mono-anionic bidentate DGs such as oxalylamide (OA), picolinamide (PA) and $N$-(2-pyridyl)sulfonamide $\left(N-\mathrm{SO}_{2} \mathrm{Py}\right)$, whereas two contributions were reported relying on the use of monodentate DGs: oxazoline and 2-pyridylsulfone derivatives. Therefore, there is still plenty room for further development in terms of both designing novel powerful and versatile DGs or discovering new types of reactivity leading to remote functionalization.

Regarding the metal source, Pd-catalysis has dominated this field. Hence, as in all fields of metal catalysis, the quest for switching from palladium to other metals, especially first-row transition metals, is a relevant driving force for innovation.

At a more fundamental level, a remaining challenge in this area is to gain an understanding of the factors that govern the regioselectivity of competing $\mathrm{C}-\mathrm{H}$ functionalization. This basic knowledge would undoubtedly contribute to design new protocols discriminating about accessible $\mathrm{C}-\mathrm{H}$ bonds present in the organic framework.

We hope that this review can contribute to stimulating new perspectives and innovative strategies in the remote directed ortho-C( $\left.\mathrm{sp}^{2}\right)-\mathrm{H}$ functionalization via catalytic cyclometalation.

\section{Conflicts of interest}

There are no conflicts to declare. 


\section{Acknowledgements}

We thank the Ministerio de Ciencia e Innovación (MICINN) (Agencia Estatal de Investigación/Project PGC2018-098660-BI00) and Fondo Europeo de Desarrollo Regional (FEDER, UE), for financial support. M. M.-M. thanks MINECO for a FPI predoctoral fellowship.

\section{Notes and references}

1 N. Kuhl, M. N. Hopkinson, J. Wencel-Delord and F. Glorius, Angew. Chem., Int. Ed., 2012, 51, 10236-10254.

2 S. De Sarkar, W. Liu, S. I. Kozhushkov and L. Ackermann, Adv. Synth. Catal., 2014, 356, 1461-1479.

3 F. Zhang and D. R. Spring, Chem. Soc. Rev., 2014, 43, 6906-6919.

4 O. Daugulis, J. Roane and L. D. Tran, Acc. Chem. Res., 2015, 48, 1053-1064.

5 S. De Sarkar, Angew. Chem., Int. Ed., 2016, 55, 10558-10560.

6 J. C. K. Chu and T. Rovis, Angew. Chem., Int. Ed., 2018, 57, 62-101.

7 T. Sawano and H. Yamamoto, J. Org. Chem., 2018, 83, 4889-4904.

8 G. Meng, N. Y. S. Lam, E. L. Lucas, T. G. Saint-Denis, P. Verma, N. Chekshin and J.-Q. Yu, J. Am. Chem. Soc., 2020, 142, 10571-10591.

9 S. Rej, Y. Ano and N. Chatani, Chem. Rev., 2020, 120, 1788-1887.

10 N. Y. S. Lam, K. Wu and J.-Q. Yu, Angew. Chem., Int. Ed., 2021, 15767-15790.

11 J. Wencel-Delord and F. Glorius, Nat. Chem., 2013, 5, 369-375.

12 T. Gensch, M. N. Hopkinson, F. Glorius and J. Wencel-Delord, Chem. Soc. Rev., 2016, 45, 2900-2936.

13 J. F. Hartwig and M. A. Larsen, ACS Cent. Sci., 2016, 2, 281-292.

14 D. J. Abrams, P. A. Provencher and E. J. Sorensen, Chem. Soc. Rev., 2018, 47, 8925-8967.

15 M. J. Caplin and D. J. Foley, Chem. Sci., 2021, 12, 4646-4660.

16 S. R. Neufeldt and M. S. Sanford, Acc. Chem. Res., 2012, 45, 936-946.

17 K. Chen and X. Lei, Curr. Opin. Green Sustainable Chem., 2018, 11, 9-14.

18 D. J. Abrams, P. A. Provencher and E. J. Sorensen, Chem. Soc. Rev., 2018, 47, 8925-8967.

19 O. Baudoin, Angew. Chem., Int. Ed., 2020, 59, 17798-17809.

20 V. K. Jain, Coord. Chem. Rev., 2021, 427, 213546.

21 Y.-F. Yang, G. Chen, X. Hong, J.-Q. Yu and K. N. Houk, J. Am. Chem. Soc., 2017, 139, 8514-8521.

22 J. Yang, Org. Biomol. Chem., 2015, 13, 1930-1941.

23 A. Dey, S. Agasti and D. Maiti, Org. Biomol. Chem., 2016, 14, 5440-5453.

$24 \mathrm{~J}$. Li, S. De Sarkar and L. Ackermann, in $\mathrm{C}-\mathrm{H}$ Bond Activation and Catalytic Functionalization I, ed. P. H. Dixneuf and H. Doucet, Springer International Publishing, Cham, 2016, pp. 217-257.

25 M. T. Mihai, G. R. Genov and R. J. Phipps, Chem. Soc. Rev., 2018, 47, 149-171.

26 A. Dey, S. K. Sinha, T. K. Achar and D. Maiti, Angew. Chem., Int. Ed., $2019,58,10820-10843$

27 S. Sasmal, U. Dutta, G. K. Lahiri and D. Maiti, Chem. Lett., 2020, 49, 1406-1420.

28 J. Le Bras and J. Muzart, Chem. Rev., 2011, 111, 1170-1214.

29 C. S. Yeung and V. M. Dong, Chem. Rev., 2011, 111, 1215-1292.

30 L. Zhou and W. Lu, Chem. - Eur. J., 2014, 20, 634-642.

31 W. Ma, P. Gandeepan, J. Li and L. Ackermann, Org. Chem. Front., 2017, 4, 1435-1467.

32 P. Gandeepan and L. Ackermann, $C-H$ Activation for Asymmetric Synthesis, John Wiley \& Sons, Ltd, 2019, pp. 239-274.
33 W. Ali, G. Prakash and D. Maiti, Chem. Sci., 2021, 12, 2735-2759.

34 Q. Wang, J. Han, C. Wang, J. Zhang, Z. Huang, D. Shi and Y. Zhao, Chem. Sci., 2014, 5, 4962-4967.

35 P. D. Legarda, A. García-Rubia, R. Gómez-Arrayás and J. C. Carretero, Adv. Synth. Catal., 2016, 358, 1065-1072.

36 I. V. Seregin, V. Ryabova and V. Gevorgyan, J. Am. Chem. Soc., 2007, 129, 7742-7743.

37 Y. Ano, M. Tobisu and N. Chatani, J. Am. Chem. Soc., 2011, 133, 12984-12986.

38 Y.-J. Liu, Y.-H. Liu, S.-Y. Yan and B.-F. Shi, Chem. Commun., 2015, 51, 6388-6391.

39 L. D. Caspers, P. Finkbeiner and B. J. Nachtsheim, Chem. - Eur. J., 2017, 23, 2748-2752.

40 G. Li, P. Liu, J. Zhang, D.-Q. Shi and Y. Zhao, Org. Chem. Front., 2017, 4, 1931-1934.

41 B. Liu, W. Ouyang, J. Nie, Y. Gao, K. Feng, Y. Huo, Q. Chen and X. Li, Chem. Commun., 2020, 56, 11255-11258.

42 B. S. Schreib, M. Fadel and E. M. Carreira, Angew. Chem., Int. Ed., $2020,59,7818-7822$.

43 M. Guan, C. Chen, J. Zhang, R. Zeng and Y. Zhao, Chem. Commun., 2015, 51, 12103-12106.

44 M. Martínez-Mingo, N. Rodríguez, R. GómezArrayás and J. C. Carretero, Org. Lett., 2019, 21, 4345-4349.

45 M. Martínez-Mingo, I. Alonso, N. Rodríguez, R. G. Arrayás and J. C. Carretero, Catal. Sci. Technol., 2021, 11, 1590-1601.

46 L.-C. Campeau, D. J. Schipper and K. Fagnou, J. Am. Chem. Soc., 2008, 130, 3266-3267.

47 D. J. Schipper, L.-C. Campeau and K. Fagnou, Tetrahedron, 2009, 65, 3155-3164.

48 P. Novák, A. Correa, J. Gallardo-Donaira and R. Martin, Angew. Chem., Int. Ed., 2011, 50, 12236-12239.

49 F.-L. Zhang, K. Hong, T.-J. Li, H. Park and J.-Q. Yu, Science, 2016, 351, 252-256.

50 F. Ma, M. Lei and L. Hu, Org. Lett., 2016, 18, 2708-2711.

51 H. Park, K. Yoo, B. Jung and M. Kim, Tetrahedron, 2018, 74, 2048-2055.

52 Q. He, Y. Ano and N. Chatani, Chem. Commun., 2019, 55, 9983-9986.

53 H. Park, P. Verma, K. Hong and J.-Q. Yu, Nat. Chem., 2018, 10, 755-762.

54 G. Hong, P. D. Nahide, U. K. Neelam, P. Amadeo, A. Vijeta, J. M. Curto, C. E. Hendrick, K. F. VanGelder and M. C. Kozlowski, ACS Catal., 2019, 9, 3716-3724.

55 T. Gogula, J. Zhang, M. R. Lonka, S. Zhang and H. Zou, Chem. Sci., 2020, 11, 11461-11467.

56 E. T. Nadres and O. Daugulis, J. Am. Chem. Soc., 2012, 134, 7-10.

57 R. Pearson, S. Zhang, G. He, N. Edwards and G. Chen, Beilstein J. Org. Chem., 2013, 9, 891-899.

58 C. Wang, C. Chen, J. Zhang, J. Han, Q. Wang, K. Guo, P. Liu, M. Guan, Y. Yao and Y. Zhao, Angew. Chem., Int. Ed., 2014, 53, 9884-9888.

59 B. V. S. Reddy, L. R. Reddy and E. J. Corey, Org. Lett., 2006, 8, 3391-3394.

60 F.-R. Gou, X.-C. Wang, P.-F. Huo, H.-P. Bi, Z.-H. Guan and Y.-M. Liang, Org. Lett., 2009, 11, 5726-5729.

61 Q. Li, S.-Y. Zhang, G. He, W. A. Nack and G. Chen, Adv. Synth. Catal., 2014, 356, 1544-1548.

62 G. He, G. Lu, Z. Guo, P. Liu and G. Chen, Nat. Chem., 2016, 8, 1131-1136.

63 C. J. Vickers, T.-S. Mei and J.-Q. Yu, Org. Lett., 2010, 12, 2511-2513.

64 Naveen, V. Rajkumar, S. A. Babu and B. Gopalakrishnan, J. Org. Chem., 2016, 81, 12197-12211.

65 J.-J. Li, R. Giri and J.-Q. Yu, Tetrahedron, 2008, 64, 6979-6987. 